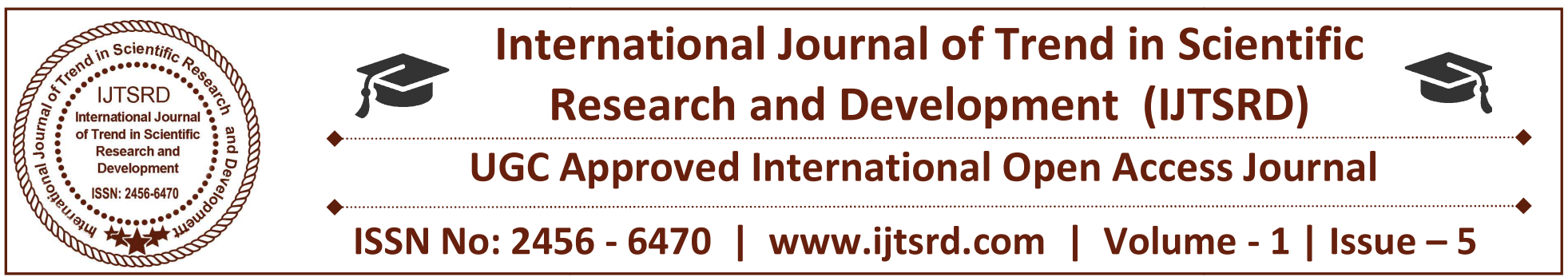

\title{
Study of The Health Status of Adolescent Boys And Girls (14-16 Years) of D N High School, Anand - Gujarat
}

\author{
Dr. Bhavana Chauhan \\ S.M.Patel College Of HomeScience, \\ Vallabh Vidyanagar, Gujarat, India
}

\section{ABSTRACT}

Malnutrition continues to be a primary cause of ill health and mortality among children in developing countries. In present study, an attempt was made to find the prevalence of malnutrition (thinness/obesity) among school children aged 14-16 years. Methods: A total of 630 students of DN High School were selected and their nutritional status was assessed by using anthropometric measurements. Results: It was observed that prevalence of Undernutrition was high in boys as compared to girls of all 3 age groups and the percentage of thinness among total boys were $16 \%$ $(n=60)$, and that of severe thinness was $11.73 \%$ $(n=44)$, whereas, among total girls percentage of thinness was $12.16 \%(n=31)$ and that of severely thinness was $3.14 \% \quad(n=8)$. When compared with socio-economic status it was observed that Undernutrition was more prevalent among middle and poor income class adolescents. Conclusion: Prevalence of malnutrition was high among boys as compared to girls especially of middle and poor income class. The study indicated the need for repeated interventions for improvement of nutrition knowledge levels in low-SES children.

\section{INTRODUCTION}

Adolescence is the time when surge of life reaches its peak. WHO identifies adolescence as the period in human growth and development that occurs after childhood and before adulthood, from ages 10 to19. Physical changes occur simultaneously with hormonal, cognitive and emotional development, thus increasing nutritional needs (11).
Numerous studies on diet and nutrition intake of adolescents in the developed world have shown that their diets are usually high in fats and refined carbohydrate (10). The behavior affecting food and drink choices seems to alter as the children become adolescents. (7)

Some dietary patterns come out common among adolescents are skipping breakfast, snacking on junk foods, decreased consumption of fruits and vegetables, lack of dairy products, wide use of fast foods / ready to use foods. $(5,1)$

Malnutrition is defined as a lack or excess intake of nutrients and/or faulty utilization of nutrients in our body, which leads to state of imbalance in the body. Malnutrition refers to both under nutrition and over nutrition. (12)

Inappropriate dietary intake during adolescence can lead to severe consequences such as Retarded physical growth, Delay sexual maturation, Iron deficiency Anemia, Stunting, Obesity, Undernutrition (Thinness), Osteoporosis, Cardiovascular diseases (2)

Overweight and obesity are a serious health problem, since they are associated with other serious diseases. The prevalence of overweight and obesity among adolescents has risen considerably within the developed countries during the past two and similar trends are being observed even in the developing world. (8)

Excess body weight can lead to diseases like atherosclerosis, hypertension, stroke, diabetes, gall bladder diseases, renal diseases and osteoarthritis of weight hearing joints and varicose veins if not present 
in adolescence period then can affect the later age. (14)

UNICEF defines under nutrition as the outcome of insufficient food intake and repeated infectious diseases. It includes being underweight for one's age, too short for one's age (stunted), dangerously thin for one's height (wasted) and deficient in vitamins and minerals (micronutrient malnutrition).

Inappropriate dietary intakes throughout adolescence will have many consequences like retard physical growth, reduce intellectual capacity, delay sexual maturation, increased risk for osteoporosis later in life. (2)

In the light of above discussion it can be summarized that adolescence is one of the most exciting yet challenging periods in human development occurring between 10 and 19 years of age. If adolescents are well nourished, they can make optimal use of their skills, talents and energies these days, and be healthy and responsible citizens and parents of healthy babies tomorrow.

OBJECTIVE: To study nutritional status of adolescents aged 14-16 years.

\section{MATERIAL AND METHODS}

In the present study we have explored health status of school- age children of 14 to 16 years. A total of 630 children of both sexes from $\mathrm{D} N \mathrm{~N}$ High School of Anand (Gujarat), India were interviewed and examined for the same. Structured, pre-designed and pre-tested questionnaire was used to interview the study participant.
Various anthropometric measurements were taken in school itself. Height, weight, waist, hip and neck circumference as well as skin fold thickness at biceps, triceps, sub scapular, supraliminal, abdominal were obtained using standard techniques.

BMI- the BMI (Body Mass Index) was calculated by using the formula mentioned below:

BMI $\left(\mathrm{Kg} / \mathrm{m}^{2}\right)=$ Weight $(\mathrm{kg}) /$ Height $\left(\mathrm{m}^{2}\right)$

Z-score for BMI for different age was calculated using LMS method and results of the same were evaluated using WHO standards to assess their growth status. According to WHO the cut offs for BMI for age are as follows.

Overweight: >+1SD (equivalent to BMI $25 \mathrm{~kg} / \mathrm{m}^{2}$ at 19 years)

Obesity: >+2SD (equivalent to BMI $30 \mathrm{~kg} / \mathrm{m}^{2}$ at 19 years)

Thinness: <-2SD

Severe thinness: $<-3$ SD.

The data thus collected was compiled and analyzed by using Microsoft Excel Software.

\section{RESULTS}

We evaluated a total of 630 students from DN High school of Anand, aged 14-16 years, of which 59.52\% $(n=375)$ were boys and $40.48(n=255)$ were girls.

Out of total boys, $45.07 \%(n=169)$ boys were 14 years old, $28.27 \%(\mathrm{n}=106)$ were 15 years old and $26.67 \%$ $(\mathrm{n}=100)$ were 16 years old. Among total girls, 30.2\% $(n=77), 26.67 \%(n=68)$ and $43.14 \%(n=110)$ belonged to age 14,15 and 16 years respectively.

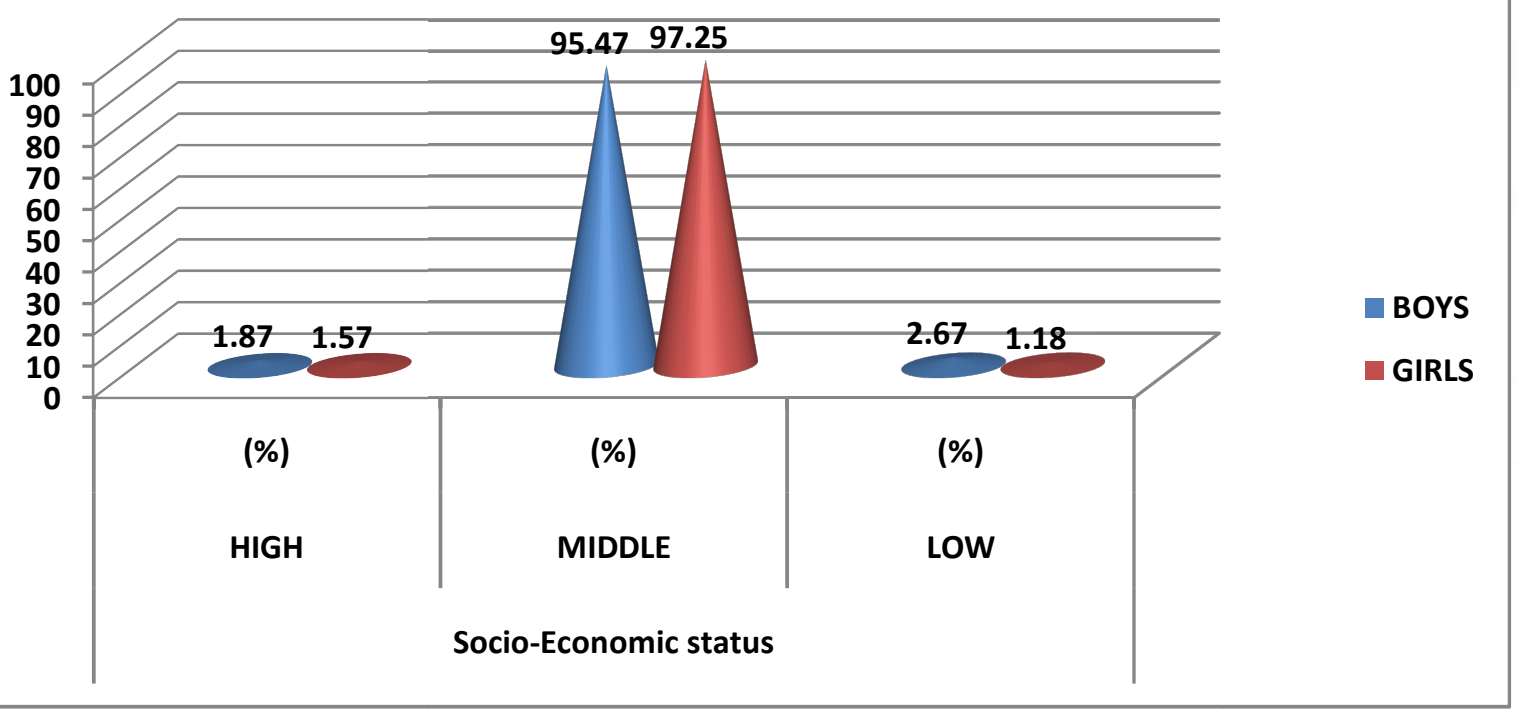

Figure-1: Socio-economic status of total male and female participants. 
International Journal of Trend in Scientific Research and Development (IJTSRD) ISSN: 2456-6470

Figure-1 presents the Socio-economic status of students; it was observed that maximum students from all 3 age group belonged to middle income class.

Table- 1: Anthropometric profile of participants (Mean \pm SD)

\begin{tabular}{|c|c|c|c|c|c|c|}
\hline \multirow[b]{2}{*}{ VARIABLE } & \multicolumn{3}{|c|}{ BOYS } & \multicolumn{3}{|c|}{ GIRLS } \\
\hline & 14 YEARS & 15 YEARS & 16 YEARS & 14 YEARS & 15 YEARS & 16 YEARS \\
\hline & $(n=169)$ & $(n=106)$ & $(n=100)$ & $(n=77)$ & $(n=68)$ & $(n=110)$ \\
\hline HEIGHT & $155.88 \pm 12.32$ & $162.4 \pm 9.16$ & $166.15 \pm 7.15$ & $153.9 \pm 5.99$ & $154.94 \pm 6.51$ & $155.53 \pm 5.85$ \\
\hline WEIGHT & $44.65 \pm 12.53$ & $50.63 \pm 14.69$ & $51.28 \pm 11.97$ & $46.19 \pm 10.14$ & $44.85 \pm 9.47$ & $47.56 \pm 10.03$ \\
\hline BMI & $19.1 \pm 14.66$ & $19 \pm 4.39$ & $18.5 \pm 3.56$ & $19.4 \pm 3.57$ & $18.6 \pm 3.49$ & $19.6 \pm 3.59$ \\
\hline $\begin{array}{c}\text { WAIST } \\
\text { CIRCUMFERENCE }\end{array}$ & $70.35 \pm 10.11$ & $73.56 \pm 12.94$ & $71.89 \pm 9.97$ & $68.76 \pm 8.01$ & $66.1 \pm 7.48$ & $67.96 \pm 8.45$ \\
\hline $\begin{array}{c}\text { HIP } \\
\text { CIRCUMFERENCE }\end{array}$ & $80.57 \pm 9.60$ & $84.09 \pm 10.10$ & $86.57 \pm 8.56$ & $83.96 \pm 8.74$ & $85.78 \pm 8.71$ & $88.4 \pm 8.74$ \\
\hline $\begin{array}{c}\text { NECK } \\
\text { CIRCUMFERENCE }\end{array}$ & $30.21 \pm 3.73$ & $31.37 \pm 2.91$ & $32.34 \pm 2.12$ & $29.12 \pm 1.92$ & $29.71 \pm 1.84$ & $29.75 \pm 1.94$ \\
\hline $\begin{array}{c}\text { LOWER } \\
\text { BODY SEGMENT }\end{array}$ & $81.68 \pm 6.86$ & $82.94 \pm 6.82$ & $87.73 \pm 5.63$ & $90.56 \pm 6.30$ & $88.28 \pm 6.12$ & $86.4 \pm 5.70$ \\
\hline \multicolumn{7}{|l|}{ CALIPERS: } \\
\hline TRICEP & $13.86 \pm 5.07$ & $14.49 \pm 5.06$ & $14.87 \pm 4.76$ & $17.56 \pm 5.56$ & $19.17 \pm 4.51$ & $20.98 \pm 5.45$ \\
\hline BICEP & $10.17 \pm 3.90$ & $10.05 \pm 3.83$ & $10.55 \pm 3.11$ & $9.33 \pm 4.05$ & $12.89 \pm 5.63$ & $15.3 \pm 5.26$ \\
\hline SUBSCAPULAR & $10.69 \pm 5.64$ & $10.15 \pm 5.75$ & $9.8 \pm 3.88$ & $13.73 \pm 5.04$ & $13.14 \pm 5.64$ & $13.92 \pm 6.21$ \\
\hline SUPRAILIAC & $12.5 \pm 7.08$ & $12.23 \pm 7.77$ & $10.38 \pm 6.23$ & $16.76 \pm 5.82$ & $15 \pm 5.08$ & $15.34 \pm 5.76$ \\
\hline ABDOMINAL & $16.36 \pm 8.56$ & $17.47 \pm 10.76$ & $15.42 \pm 7.95$ & $20.76 \pm 6.73$ & $19.32 \pm 5.90$ & $18.97 \pm 6.45$ \\
\hline
\end{tabular}

Table-1 presents mean anthropometric profile of participants.

Table-2: Age and Sex wise growth assessment of participants.

\begin{tabular}{|c|c|c|c|c|c|c|c|c|c|c|c|c|c|c|c|c|c|c|c|c|}
\hline \multirow[t]{3}{*}{$\begin{array}{c}\text { AGE } \\
\text { GROUP } \\
\end{array}$} & \multicolumn{10}{|c|}{ BOYS } & \multicolumn{10}{|c|}{ GIRLS } \\
\hline & \multicolumn{2}{|c|}{$\begin{array}{c}\text { SEVERELY } \\
\text { THIN }\end{array}$} & \multicolumn{2}{|c|}{ THIN } & \multicolumn{2}{|c|}{ NORMAL } & \multicolumn{2}{|c|}{$\begin{array}{c}\text { OVER } \\
\text { WEIGHT }\end{array}$} & \multicolumn{2}{|c|}{ OBESE } & \multicolumn{2}{|c|}{$\begin{array}{l}\text { SEVEREL } \\
\text { Y THIN }\end{array}$} & \multicolumn{2}{|c|}{ THIN } & \multicolumn{2}{|c|}{ NORMAL } & \multicolumn{2}{|c|}{$\begin{array}{c}\text { OVER } \\
\text { WEIGHT }\end{array}$} & \multicolumn{2}{|c|}{ OBESE } \\
\hline & $\mathbf{N}$ & $\%$ & $\mathbf{N}$ & $\%$ & $\mathbf{N}$ & $\%$ & $\mathbf{N}$ & $\%$ & $\mathbf{N}$ & $\%$ & $\mathbf{N}$ & $\%$ & $\mathbf{N}$ & $\%$ & $\mathbf{N}$ & $\%$ & $\mathbf{N}$ & $\%$ & $\mathbf{N}$ & $\%$ \\
\hline 14 YRS & 22 & 13.02 & 23 & 13.61 & 100 & 59.17 & 17 & 10.06 & 7 & 4.14 & 4 & 5.19 & 5 & 6.49 & 54 & 70.13 & 13 & 16.88 & 1 & 1.3 \\
\hline 15 YRS & 9 & 8.49 & 18 & 16.98 & 58 & 54.72 & 12 & 11.32 & 9 & 8.49 & 4 & 5.88 & 12 & 17.65 & 45 & 66.18 & 6 & 8.82 & 1 & 1.47 \\
\hline 16 YRS & 13 & 13 & 19 & 19 & 57 & 57 & 9 & 9 & 2 & 2 & 0 & 0 & 14 & 12.73 & 83 & 75.45 & 11 & 10 & 2 & 1.82 \\
\hline TOTAL & 44 & 11.73 & 60 & 16.00 & 215 & 57.33 & 38 & 10.13 & 18 & 4.80 & 8 & 3.14 & 31 & 12.16 & 182 & 71.37 & 30 & 11.76 & 4 & 1.57 \\
\hline
\end{tabular}

Nutritional status according to age is given in Table-2. It was observed that undernourishment was high among males as compared to females while the reverse in the case of normal children. 
International Journal of Trend in Scientific Research and Development (IJTSRD) ISSN: 2456-6470

Table-3: Effect of Socio-economic status on BMI of participants.

\begin{tabular}{|c|c|c|c|c|c|c|c|c|c|c|c|c|}
\hline \multirow[t]{3}{*}{ SES } & \multicolumn{6}{|c|}{ BOYS } & \multicolumn{6}{|c|}{ GIRLS } \\
\hline & \multicolumn{2}{|c|}{$\begin{array}{c}\text { UNDER } \\
\text { WEIGHT }\end{array}$} & \multicolumn{2}{|c|}{ NORMAL } & \multicolumn{2}{|c|}{$\begin{array}{c}\text { OVER } \\
\text { WEIGHT }\end{array}$} & \multicolumn{2}{|c|}{$\begin{array}{c}\text { UNDER } \\
\text { WEIGHT }\end{array}$} & \multicolumn{2}{|c|}{ NORMAL } & \multicolumn{2}{|c|}{$\begin{array}{c}\text { OVER } \\
\text { WEIGHT }\end{array}$} \\
\hline & $\mathbf{N}$ & $\%$ & $\mathbf{N}$ & $\%$ & $\mathbf{N}$ & $\%$ & $\mathbf{N}$ & $\%$ & $\mathbf{N}$ & $\%$ & $\mathbf{N}$ & $\%$ \\
\hline$\underline{\underline{\mathrm{RICH}}}$ & & & & & & & & & & & & \\
\hline 14 YRS & 0 & 0 & 2 & 100 & 0 & 0 & 1 & 50 & 1 & 50 & 0 & 0 \\
\hline $15 \mathrm{YRS}$ & 0 & 0 & 0 & 0 & 2 & 100 & 0 & 0 & 1 & 100 & 0 & 0 \\
\hline $16 \mathrm{YRS}$ & 1 & 33.33 & 1 & 33.33 & 1 & 33.33 & 0 & 0 & 1 & 100 & 0 & 0 \\
\hline TOTAL & 1 & 14.29 & 3 & 42.86 & 3 & 42.86 & 1 & 25 & 3 & 75 & 0 & 0 \\
\hline$\frac{\text { MIDDLE }}{\text { CLASS }}$ & & & & & & & & & & & & \\
\hline 14 YRS & 53 & 32.52 & 91 & 55.83 & 19 & 11.66 & 10 & 13.89 & 50 & 69.44 & 12 & 16.67 \\
\hline $15 \mathrm{YRS}$ & 33 & 33 & 51 & 51 & 16 & 16 & 19 & 28.36 & 43 & 64.18 & 5 & 7.46 \\
\hline $16 \mathrm{YRS}$ & 41 & 43.16 & 47 & 49.47 & 7 & 7.37 & 20 & 18.35 & 77 & 70.64 & 12 & 11.01 \\
\hline TOTAL & 127 & 35.47 & 189 & 52.79 & 42 & 11.73 & 49 & 19.76 & 170 & 68.55 & 29 & 11.69 \\
\hline $\begin{array}{l}\text { POOR } \\
\text { CLASS }\end{array}$ & & & & & & & & & & & & \\
\hline 14 YRS & 3 & 75 & 1 & 25 & 0 & 0 & 1 & 33.33 & 2 & 66.67 & 0 & 0 \\
\hline 15 YRS & 2 & 50 & 1 & 25 & 1 & 25 & 0 & 0 & $\mathbf{0}$ & 0 & 0 & 0 \\
\hline 16 YRS & 2 & 100 & 0 & 0 & 0 & 0 & 0 & 0 & $\mathbf{0}$ & $\mathbf{0}$ & 0 & 0 \\
\hline TOTAL & 7 & 70 & 2 & 20 & 1 & 10 & 1 & 33.33 & 2 & 66.67 & 0 & 0.00 \\
\hline
\end{tabular}

Table-3 presents the effect of socio-economic status on BMI of participants. We found that prevalence of Undernutrition was high among middle and poor income class, and percentage of Undernutrition among boys were high as compared to girls.

\section{DISCUSSION}

As per WHO standards, it was observed that Prevalence of severe thinness was high in Boys of all 3 age group as compared to girls, and thinness was seen high in 14 and 16 years boys as compared to girls and vice versa in 15 years students. The underlying reason for Under nutrition can be insufficient supply of calories and nutrients as per demand.

Comparing the BMI with SES we observed that prevalence of Under nutrition was high among Middle income and poor income group and Boys of middle and poor income were found under weight as compared to girls of all 3 age group.

Similar studies were conducted earlier which supports our findings:
Among undernourished children, males dominate the females while the reverse in the case of normal children. (9)

In one study, it was observed that prevalence of under-nutrition in both male and female was 44.56 and $37.32 \%$ respectively. The prevalence of chronic malnutrition (stunting) in male was $26.31 \%$ and in females was $21.37 \%$. The prevalence of acute malnutrition in both males and females according to the BMI-for-age was $38.24 \%$ and $34.05 \%$ respectively (13).

A study conducted among school students of rural Goa found that More boys were underweight than girls $(p<0.001)$ and under-nutrition was uniform across all the years of schooling (3). 
In our study it was observed that obesity was less prevalent as compared to Undernutrition among all students, however the percentage of overweight girls was high in 14 and 16 years students as compared to boys and in 15 years old, percentage of overweigh boys was high as compared to girls, whereas prevalence of obesity was seen high in boys of all 3 age group as compared to girls. The underlying reason for overweigh and obesity can be change in life style and over consumption of fast foods, confectionary foods and carbonated beverages.

Study on Nutritional Status of Adolescents in Rural Wardha concluded- Majority (53.8\%) of the adolescents in this study area are thin and only $2.2 \%$ were overweight, thus it supports our study (6).

\section{CONCLUSION}

Malnutrition among children is the major public health problem in India. Socio-economic status has very high impact on nutritional status of adolescents. In the present study we observed that prevalence of malnutrition was high among boys as compared to girls. Whereas undernutrition was more prevalent among middle and poor income class adolescents.

\section{RECOMMENDATIONS}

$>$ It is recommended that future studies use longitudinal data to observe pathways between relative socioeconomic status and health during adolescence and into adulthood.

$>$ The study indicated the need for repeated interventions for improvement of nutrition knowledge levels in low-SES children.

The nutritional literacy among students should be assessed with regards to their food habits.

\section{REFERENCES}

1) Arya G, Mishra S. Effect of Junk Foods and Beverages on Adolescent's Health. IOSR Journal of Nursing and Health Science (IOSRJNHS), 1940 Volume 1, Issue 6 (Jul-Aug 2013): 26-32.

2) Adolescent Nutrition: A Review Of The Situation In Selected South-East Asian Countries. World Health Organization, New Dehli, 2006:1-84.

3) Banerjee S, Dias A, Shinkre R, Patel V. UnderNutrition Among Adolescents: A Survey In Five Secondary Schools In Rural Goa. The National
Medical Journal of India 2011, VOL. 24, NO. 1:811.

4) Chakraborty S. Identity Styles of Adolescents in Schools and Their Cognitive and Affective Functioning. http://hdl.handle.net/10603/29317, Nov 2014.

5) Demory D, Motil KJ. Adolescent Eating Habits. http://www.uptodate.com/contents/adolescenteating-habits, 2015.

6) Deshmukh PR, Gupta SS, Bharambe MS, Dongre AR, Maliye C, Kaur S, Garg BS. Nutritional Status Of Adolescents In Rural Wardha Indian. Indian Journal of Pediatrics, Volume 73February, 2006:139-141.

7) Henningsen M. Dietary Habits in Adolescence related to Sociodemographic Factors, Physical Activity and Self-Esteem. Norwegian University of Science and Technology, NTNU, 2011: 7-54.

8) Jain G. To Study The Problem Of Obesity Among School Children 1314 Year In Relation To Socio Economic Status Eating Habits And Physical. http://hdl.handle.net/10603/29353, Nov,2014.

9) Joshi HS, Gupta R, Joshi M C, Mahajan V. Determinants of Nutritional Status of School Children - A Cross Sectional Study in the Western Region of Nepal.NJIRM 2011; Vol. 2(1): 10-15.

10) Kotecha PV, Patel SV, Baxi RK, Mazumdar VS, Misra S, Mehta KG, Diwanji M, Modi E. Dietary Pattern Of School going Adolescents In Urban Baroda, India. J Health Popul Nutr, 2013 Dec;31(4):490-496.

11) Maziya N. Adolescent Nutritional Status and its Association with Village-Level Factors in Tanzania. http://scholarworks.umass.edu/theses, February 2014:1-65.

12) Rani K. Effect of Socioeconomic Status and Dietary Factors on Nutritional Status of Adolescents. IGNOU, 2014.

13) Singh JP, Kariwal P, Gupta SP, Singh AK, Imtiaz D. Nutritional Status and Morbidity among School Going Children: A Scenario from a Rural India. Sch. J. App. Med. Sci., 2014; 2(1D):379-383.

14) Singh R. Fear Of Fatness And Adolscenet Girls Implications For Obesity. Bundelkhand University, http://hdl.handle.net/10603/24365, September, 2014 